\title{
Estruturas de governança em arranjos produtivos locais: um estudo comparativo nos arranjos calçadistas e sucroalcooleiro no estado de São Paulo
}

\author{
Mário Sacomano Neto \\ Universidade Metodista de Piracicaba \\ Luiz Fernando de Oriani e Paulillo \\ Universidade Federal de São Carlos
}

\begin{abstract}
A governança nos arranjos produtivos refere-se ao modo de coordenação, comando, intervenção e participação dos atores do arranjo. Devido ao significativo aumento do interesse da política pública em arranjos produtivos locais no Brasil, é oportuno compreender essa variação e/ou interdependência de governança de cada arranjo territorial. O presente artigo compara estruturas de governança em três arranjos produtivos locais (APLs): a) Birigui (calçados infantis), b) Jaú (calçados femininos) e c) Piracicaba (APL do álcool). A coleta de dados em organizações de interesses e em 31 empresas dos três arranjos paulistas foi realizada por entrevistas em profundidade in loco nas empresas. No artigo são identificadas as influências distintas nas governanças dos arranjos produtivos. Os resultados da pesquisa revelam: 1) a governança teve interferência positiva na cooperação e no desenvolvimento de empresas; 2) as possibilidades de desenvolvimento dos APLs dependem em grande parte das formas de governança pública ou privada; 3) as governanças desses arranjos produtivos locais são heterogêneas, complexas e, em alguns casos, interdependentes com outras distintas; e 4) os atores coordenadores dos arranjos determinam as relações, recursos e regras, propondo novas ordens institucionais e organizacionais.
\end{abstract}

Palavras-chave: arranjos produtivos locais; política pública; governança; cooperação; ganhos coletivos; territórios.

Estructuras de gobernanza en arreglos productivos locales: un estudio comparativo en los arreglos calzadistas y sucroalcoholero en el estado de São Paulo

La gobernanza en los arreglos productivos se refiere al modo de coordinación, comando, intervención y participación de los actores del arreglo. Debido al significativo aumento del interés de la política pública en arreglos productivos locales en Brasil es oportuno comprender esa variación y/o interdependencia de gobernanza de cada arreglo territorial. El presente artículo compara las estructuras de gobernanza en tres arreglos productivos locales (APLs): a) Birigui (calzados infantiles), b) Jaú (calzados femeninos) y c) Piracicaba (APL del alcohol). La recolección de datos en organizaciones de

Artigo recebido em 23 dez. 2010 e aceito em 28 jun. 2011. Agradecemos o apoio financeiro concedido pela Fapesp. 
intereses y en 31 empresas de los tres arreglos paulistas fue realizada por entrevistas en profundidad in loco en las empresas. En el artículo se identifican las diferentes influencias en las gobernanzas de los arreglos productivos. Los resultados de la encuesta revelan: 1) la gobernanza tuvo interferencia positiva en la cooperación y el desarrollo de las empresas; 2) las posibilidades de desarrollo de los APLs dependen en gran parte de las formas de gobernanza pública o privada; 3) las gobernanzas de esos arreglos productivos locales son heterogéneas, complejas y, en algunos casos, interdependientes con otras distintas; y 4) los actores coordinadores de los arreglos determinan las relaciones, recursos y reglas, proponiendo nuevos órdenes institucionales y organizacionales.

Palabras clave: arreglos productivos locales; política pública; gobernanza; cooperación; ganancias colectivas; territorios.

Governance structures in clusters: a comparative study in footwear and sugarcane's arrangements in the state of São Paulo

Governance in clusters refers to the mode of coordination, control, intervention and participation of actors from the local arrangement. Due to the significant increase in the interest of public policy in local clusters is desirable to understand the mode of coordination, command and stakeholder participation in these arrangements. This paper compares the governance structures in three local productive arrangements (APLs): Birigui (children's shoes), Jau (women's shoes) and Piracicaba (APL alcohol). The data collection in institutions and 31 companies of the arrangements, was conducted by in-depth interviews company on site. In the article we identify different influences on the coordination of arrangements, as the government, unions and big business sectors. The survey results reveal: 1) governance had positive interference on cooperation and business development, 2) the potential development of clusters depends largely on the forms of governance, public or private; 3 ) the governing of local clusters are heterogeneous and complex, and 4) powerful actors holders of coordination arrangements, determine the relationships, resources and rules, proposing new institutional orders. In this sense this paper contributes to the understanding the set of relationships and influential institutions related with the clusters governance.

KEY WORDs: local clusters; clusters; governance; cooperation; collective gains; territories.

\section{Introdução}

As primordiais ideias sobre aglomeração de empresas foram publicadas por Alfred Marshall, no livro Principles of economics, em 1920. O aspecto central do estudo de Marshall refere-se aos ganhos gerados por fatores locacionais, geralmente associados a circunstâncias geográficas e condições físicas (clima, solo etc.) e à proximidade do mercado consumidor (Marshall, 1988) .

Marshall lança um corolário nos estudos de aglomerações relativo às possibilidades de obter ganhos coletivos de atividades geograficamente concentradas. Essas reflexões iniciais de Marshall despertaram discussões sobre a importância da concentração espacial para o desenvolvimento econômico e social (Milanez e Puppim, 2009), emprego (Brito et. al, 2010) e geração de vantagens competitivas (Souza e Arica, 2006) não verificadas se as empresas estivessem atuando de forma isolada. Em paralelo, surgiram também novas reflexões sobre o 
delineamento de políticas públicas ligadas aos benefícios das aglomerações ou arranjos produtivos locais (Barroso e Soares, 2009).

A partir desses primeiros estudos, as formas de aglomerações de empresas foram analisadas por diversos pesquisadores em diferentes contextos históricos e geográficos, inclusive com pressupostos epistemológicos distintos. Por esse fato, a terminologia relativa a aglomerações de empresas é bastante confusa e controversa. Conforme mencionam Lastres e Cassiolato (2005), existem outros termos inerentes aos estudos de aglomerações, como: cadeia produtiva, clusters, distritos industriais, milieu inovador, polos, parques científicos e tecnológicos e redes de empresas.

No Brasil, o termo Arranjo Produtivo Local (APL) foi criado pelo governo federal - em um grupo interministerial de 2004 - para prover políticas públicas específicas para as aglomerações de empresas (Noronha e Turchi, 2005), inclusive muitas já existentes no Brasil. Essa forma de política pública de estímulo ao desenvolvimento territorial passou a apoiar os vínculos verticais e horizontais entre empresas. A política pública centrada nos APLs deixou de lado a velha classificação de empresas por setor, limitada por sua abordagem centrada apenas na similaridade de produtos concorrentes e incapaz de verificar cooperações verticais e horizontais, entre empresas e essas outras organizações (Noronha e Turchi, 2005).

Com o desenvolvimento recente desses APLs e das políticas públicas voltadas para essas organizações, a interpretação sobre a força do desenvolvimento endógeno mudou. Não é possível interpretar tais arranjos como Marshall classificou. Atualmente, a governança tem significativa influência em um APL. Assim, se há algo novo na localidade que produz, ela brota de uma forma específica de governança, podendo envolver mais ou menos tecnologia, mais ou menos política pública e, certamente, uma nova organização (mais ou menos aberta, mais ou menos flexível, mais ou menos institucionalizada e mais ou menos política). Nesse sentido, o desenvolvimento de um APL depende fortemente dos atores e suas relações de poder.

Um APL é formado por um campo institucional de atores mais ou menos poderosos em influenciar a coordenação e a articulação entre empresas em um determinado território. Os aspectos institucionais e as relações de forças entre os atores influenciam o desenvolvimento regional e as competitividades dessas empresas (Noronha e Turchi, 2005; Paulillo, 2000). Por esse fato, o estudo das formas de governança em APLs tem recebido atenção de diversos pesquisadores no Brasil (Vilpoux e Oliveira, 2010; Villela e Pinto, 2009; Tapia, 2005; Garcia, Motta e Amato Neto, 2004; Suzigan, Garcia e Furtado, 2002) e no exterior (Svensson, Nordin e Flagestad, 2005).

O presente artigo busca comparar as estruturas de governança em três arranjos produtivos locais: APL de Birigui (para produção de calçados infantis), APL de Jaú (calçados femininos) e APL de Piracicaba (indústria de bens de capital para a produção de etanol). Ao comparar as estruturas de governança atém-se ao papel dos atores privados e também dos públicos. Esses últimos tornaram-se importantes para apoiar ou restringir o desenvolvimento do sistema produtivo.

Para compor a análise comparativa desses três casos são utilizadas cinco categorias de análise para a estrutura de governança nos APLs: 1) governança pública; 2) governança pri- 
vada; 3) governança de ator coletivo; 4) governança a montante; e 5) governança a jusante. O artigo também busca classificar e comparar as governanças dos arranjos conforme as dimensões apresentadas por Storper e Harrison (1991) e Gereffi (1999). A categorização proposta busca então compreender as diversas influências, públicas e privadas, incluindo os atores coletivos, nas governanças desses arranjos produtivos locais do estado de São Paulo.

Assim, o presente trabalho procura mostrar a complexidade relativa à questão da governança em APLs e que isso passa pela possibilidade de interdependências entre governanças distintas no mesmo arranjo e pela especificidade da construção coletiva em cada localidade ou território produtivo. Curioso é verificar como as governanças estabelecidas buscam e alcançam políticas públicas também distintas para cada arranjo, provavelmente porque cada governança produtiva local assimila ou realiza um processo de adaptação institucional diferenciado.

\section{Arranjos Produtivos Locais (APLs)}

Os aglomerados territoriais despontaram como importantes sistemas produtivos capazes de enfrentar os problemas e dificuldades referentes à necessidade de modernização e ao desenvolvimento de setores e regiões (Milanez e Puppim, 2009). Os distritos industriais, clusters, milieu inovativo, sistemas produtivos, sistemas locais, nacionais e regionais de inovação, arranjos produtivos, entre outros, são alguns sistemas que evidenciam as economias de aglomeração e a cooperação entre empresas e instituições como formas de aumento de competitividade.

Os APLs emergem como importantes sistemas de relações intra e interempresas e instituições, envolvendo aglomerações territoriais de agentes econômicos, políticos e sociais. Conforme definido pelo Sebrae (2007):

APLs são aglomerações de empresas localizadas em um mesmo território, que apresentam especialização produtiva e mantêm algum vínculo de articulação, interação, cooperação e aprendizagem entre si e com outros atores locais tais como governo, associações empresariais, instituições de crédito, ensino e pesquisa.

Noronha e Turchi (2005:3) conceituam APL como um tipo específico de arranjo institucional. O termo APL, que tem como principais características a "produção especializada, delimitada a uma região", possui vantagens operacionais importantes. Seu conceito diferencia-se, por exemplo, de abordagens como da cadeia produtiva, que enfatiza a relação vertical de sistemas produtivos, independentemente de sua delimitação espacial.

Então, os arranjos produtivos envolvem concentração de quaisquer atividades similares ou interdependentes no espaço, não importando o tamanho das empresas, nem a natureza da atividade econômica, podendo esta pertencer ao setor primário, secundário ou, até mesmo, terciário, variando desde estruturas artesanais, com pequeno dinamismo, até arranjos que 
comportem grande divisão do trabalho entre as firmas e produtos. Um APL pode englobar uma cadeia produtiva estruturada localmente ou concentrar-se em um ou alguns elos de uma cadeia produtiva de maior abrangência espacial, seja ela regional, nacional ou até mesmo internacional.

Porém, independente do termo a ser utilizado, deve-se apontar, segundo Chiochetta (2005), que esses arranjos ou sistemas geralmente incluem empresas produtoras de bens e serviços, fornecedoras de equipamentos e outros insumos, prestadoras de serviços, representantes comerciais, revendedoras, clientes, cooperativas, associações e demais organizações, que se dedicam à formação e ao treinamento de recursos humanos, informação, pesquisa e desenvolvimento, promoção e financiamento.

O interesse para o fenômeno do arranjo produtivo local não é recente. Muito pelo contrário, a argumentação da economia neoclássica já estava atenta desde o início do século XX para os benefícios do desenvolvimento endógeno que propiciaria produção, crescimento econômico e desenvolvimento local. Os distritos industriais são os casos clássicos das primeiras regiões ganhadoras: os distritos marshallianos (definidos a partir dos preceitos da economia clássica, principalmente por Alfred Marshall, cristalizados fielmente nas experiências de desenvolvimento regional de forma endógena, como o caso da Terceira Itália, em que as relações de proximidade e a cultura específica de seus atores sociais possibilitaram os ganhos da região (Paulillo, 2000). Posteriormente, estudiosos da regulação governamental chamaram a atenção para regiões produtivas que emergiram pautadas em intensas relações das empresas com os governos centrais para alcançar recursos (como subsídios, facilidades de ordem jurídica e administrativa etc.), na qual a organização endógena (o distrito clássico) pouco importava e a hierarquização estabelecida com o governo central importava em demasia (Paulillo, 2000).

Assim, já na fase de domínio do modo de regulação estatal no capitalismo, muitas regiões produtivas estabeleceram resultados positivos amparadas em estruturas de decisões ancoradas na velha estrutura política territorial (políticas de "cima para baixo"). Nessas experiências regionais, o governo central e a ação estatal bastavam para as regiões ganhadoras, e a governança (políticas de "baixo para cima") pouco ou nada pesava. Os casos da regulação francesa são os melhores exemplos. Após os anos 1970, com os avanços dos processos de internacionalização do capital, de fragmentação estatal e de desregulamentação e o advento do pós-fordismo produtivo, os arranjos produtivos ganharam outra ênfase organizacional. A novidade resultava das construções sociais e políticas amparadas em processos de competição - emulação - cooperação, num grau de complexidade institucional nunca vista antes (Paulillo, 2000). Nesse movimento, as governanças surgiram como a novidade da organização produtiva local. Com maiores ou menores abertura, flexibilidade e organização para construir políticas públicas, essas formas de governança podem atuar isoladamente ou articuladas com outras distintas. É possível uma governança de atores privados (envolvendo grandes empresas detentoras de poder de influência no arranjo) ser muito interdependente com uma governança pública (que já envolveria atores públicos como prefeituras municipais, secretarias estaduais e municipais, ministérios federais etc.). Ou uma governança de atores coletivos (com entidades de representação coletiva como sindicatos, associações de interesses, Sebrae, Senai etc.) ser 
muito interdependente com a governança a montante de um arranjo produtivo (envolvendo fornecedores das empresas desse arranjo com influência no processo de coordenação local). Essas interdependências entre governanças podem representar uma luz à interpretação do processo de desenvolvimento de APLs.

Devido ao significativo aumento do interesse da política pública em arranjos produtivos locais no Brasil, é oportuno compreender essa variação e/ou interdependência de governança de cada arranjo territorial, que podem envolver comando, influência, instituições ad hoc e participações (mais horizontais) dos atores produtivos locais.

\section{Formas de governança em arranjos produtivos locais}

Nos arranjos produtivos locais a governança refere-se aos

diferentes modos de coordenação, intervenção e participação, nos processos de decisão dos diferentes atores - Estado, em seus vários níveis, empresas, cidadãos e trabalhadores, organizações não governamentais etc.; e das diversas atividades que envolvem a organização dos fluxos de produção e comercialização, assim como o processo de geração, disseminação e uso de conhecimentos (Lastres e Cassiolato, 2005:12).

Para Suzigan, Garcia e Furtado (2002), a governança também se refere ao grau de hierarquia, liderança e comando (ou, alternativamente, colaboração e cooperação) entre os atores.

Storper e Harrison (1991:408) entendem a forma de governança a partir do "ator que exerce poder de afetar o desenvolvimento do sistema". Os autores utilizam "sistema de produção" para designar a estrutura de coordenação que se forma a partir das relações horizontais e verticais das firmas. Essas relações podem ser governadas por mecanismos de mercado ou por processos interativos conformados em fortes hierarquias entre os atores. Conforme destacam Suzigan, Garcia e Furtado (2002), faz-se necessário verificar se as relações são governadas por mecanismos de preços ou são resultado de um processo de imposição dos atores mais poderosos da cadeia.

Storper e Harrison (1991) elaboraram uma classificação das estruturas de governança. Para entender as relações de poder foi utilizada a denominação centro e anel (core and ring) para evidenciar o poder das grandes empresas sobre os fornecedores. Por centro, os autores entendem "a situação onde o poder é assimétrico ou algumas empresas têm a habilidade de determinar a existência de outra". Por anel, os autores entendem que "o poder é simétrico e a existência de empresas não é determinada por decisões de outras empresas" (Storper e Harrison, 1991:412). A partir desses três conceitos, os autores destacam quatro tipos de estruturas de governança utilizadas neste artigo para classificar os arranjos:

1) All ring no core - Nessa estrutura de governança não há nenhuma firma líder. Não há hierarquia (Storper e Harrison, 1991). Sistema produtivo sem diferenças e liderança entre os 
atores (ex.: distritos industriais italianos da década de 1980). Embora os estudos recentes mostrem que atualmente nos distritos industriais italianos foram incorporadas relações assimétricas de subcontratação (Suzigan, Garcia e Furtado, 2002).

2) Core-ring with coordinating firm - Sistema com certo grau de hierarquia. Decorre de certa influência sistemática de algumas firmas sobre outras. Entretanto, não é determinante para a sobrevivência das outras empresas (ex.: Bosch, Benetton).

3) Core-ring with lead firm - Sistema onde a empresa líder tem substancial independência dos fornecedores e capacidade de reconfigurar parte do anel de subcontratados. O poder é assimétrico e há considerável hierarquia. Nesse sistema a firma líder é dominante, isto é, os participantes dependem da estratégia do líder (ex.: Toulouse Aircraft, Hollywood, Snecma).

4) All-core - Sistema e firma verticalmente integrados. Todas as tarefas de produção e distribuição de mercadorias são assumidas por uma grande empresa verticalizada.

As estruturas de governança intermediárias (2 e 3) são as formas mais comuns de coordenação das atividades produtivas, conforme indicam Suzigan, Garcia e Furtado (2002). Isso também se efetiva em função do processo de desverticalização presente em certas estratégias empresariais.

Outro ponto importante sobre a governança refere-se à investigação da inserção das estruturas localizadas em um contexto mais amplo. É o que Gereffi (1999) chamou de cadeias produtivas locais (global commodity chains). O autor busca, por meio de uma análise do formato organizacional das cadeias produtivas internacionais, investigar as hierarquias e formas de governança na cadeia. Um dos pontos centrais é que a apropriação do valor pago entre os agentes se configura de forma simétrica. A capacidade de comandar redes de empresas localizadas faz com que o valor gerado ao longo dos processos seja apropriado pelos grandes compradores internacionais.

As dimensões utilizadas por Gereffi (1999) para análise da governança são as seguintes: 1) cadeia e valor agregado; 2) dispersão geográfica das redes de produção e de marketing nos âmbitos nacional, regional e global; 3) estrutura de governança pautada em relações de autoridade ou poder entre as firmas, as quais determinam as alocações de recursos financeiros, materiais e humanos ao longo da cadeia; 4) arcabouço institucional que identifica como as condições políticas locais agem em cada estágio da cadeia global. Desta forma, o autor identifica dois tipos de cadeias:

1) Producen-driven - cadeias dirigidas pelo produtor (como nas indústrias de metal-mecânica, eletrônica, química, desenvolvimento de produtos e processos etc.);

2) Buyer-driven - cadeias dirigidas pelo comprador (como têxtil, vestuário, calçados, móveis e alimentos etc.) ou por empresas que possuem a marca, canais de comercialização e distribuição. 
Esses formatos correspondem a diferentes tipos de estruturas de governança, determinada pela capacidade da firma em deter ativos estratégicos que não sejam reproduzidos pelos outros agentes da cadeia.

A governança também contempla os aspectos contratuais que regem as interações entre agentes e envolvem tanto mecanismo de incentivo que estimula a interação como também formas particulares de resolução dos conflitos (Britto, 2002). O autor menciona que os ganhos coletivos obtidos vão além da dimensão técnico-produtiva e envolvem a capacidade e a competência de enfrentar, de forma coordenada, a instabilidade e a competição dos negócios.

Lastres e Cassiolato (2005) também verificam dois tipos de formas de governança em APLs, que são: 1) as hierárquicas, onde a autoridade é internalizada dentro de grandes corporações com capacidade de coordenação das atividades (tecnológicas, produtivas e mercadológicas) e 2) a governança não hierárquica, caracterizada pela existência de pequenas e médias empresas onde poucos atores são dominantes e a coordenação prevalecente é horizontal, envolvendo características que complementam contratos, como confiança, influência, liderança e redes de articulação (Menard, 2004).

Com base nesse referencial teórico, o presente trabalho foca categorias de análise específicas para governanças em APLs. Na pesquisa de campo dos arranjos selecionados para análise, foram enfocados os âmbitos local, estadual, nacional e internacional para, a partir daí, caracterizar as governanças locais sob as seguintes dimensões: 1) governança pública (envolvendo atores públicos como prefeituras municipais, secretarias estaduais e municipais, ministérios federais etc.); 2) governança privada (envolvendo grandes empresas detentoras de poder de influência no arranjo); 3) governança de ator coletivo (com entidades de representação coletiva como sindicatos, associações de interesses, Sebrae, Senai etc.); 4) governança a montante (envolvendo fornecedores das empresas do arranjo com influência no processo de coordenação local); 5) governança a jusante (com distribuidores e clientes possuidores de poder de barganha nas negociações com as empresas do arranjo local). Com essa classificação foi possível contemplar as questões de coordenação de cada arranjo. Essa classificação e seu movimento metodológico foi constituída a partir das contribuições de vários autores, como Gereffi (1999), Suzigan, Garcia e Furtado (2002), Storper e Harrison (1991), Humphrey e Schmitz (2000), Cassiolatto e Szapiro (2002) e Lastres e Cassiolato (2005).

\section{Metodologia e coleta de dados}

Quanto ao método e delineamento, a pesquisa é classificada como qualitativa, e quanto ao tipo de pesquisa, pode ser classificada como exploratória (Collins e Hussey, 2005). Como os arranjos produtivos locais envolvem complexas relações entre empresas e instituições, significados, relações de poder, atores, interesses e pessoas, esse recorte metodológico apresentouse o mais adequado para a condução da pesquisa.

A observação e a comparação são as técnicas de pesquisa do presente estudo, conforme definido por Cervo, Bervian e Da Silva (2007). Como destacam os autores, a observação sistemática e a não participante são as técnicas que mais se aproximam desta pesquisa. A observa- 
ção sistemática tem como característica básica o planejamento prévio e a observação estruturada. Já na observação não participante o pesquisador se mantém na posição de observador, sem deixar se envolver com o objeto da observação (Cervo, Bervian e Da Silva, 2007).

A amostra foi selecionada por conveniência. Buscou-se a melhor representatividade da amostra, sem a preocupação em testar hipóteses. Foram pesquisadas, ao todo, 31 empresas, 10 empresas no Arranjo Produtivo Local de Birigui (APLB), 10 empresas no Arranjo Produtivo Local de Jaú (APLJ) e 11 empresas no Arranjo Produtivo Local do Álcool de Piracicaba (Apla). As associações de classe dos três arranjos também fizeram parte da coleta de dados. As entrevistas, quando permitido, foram gravadas, e tiveram como eixo um roteiro de entrevistas semiestruturado.

\section{Resultados da pesquisa}

Esse subitem apresenta a governança em cada arranjo com base nas categorias de análise para a estrutura de governança nos APLs, como: 1) governança pública; 2) governança privada; 3) governança de ator coletivo; 4) governança a montante e 5) governança a jusante.

\subsection{Governança do arranjo produtivo local de Birigui}

Em 2006, foi formalizado o "Convênio do APL" entre o Sindicato das Indústrias do Calçado e Vestuário de Birigui (Sinbi), a Secretaria de Desenvolvimento Econômico, Ciência e Tecnologia do Estado e o Sebrae. Esse projeto inclui 33 micro e pequenas empresas montadoras de calçados. O sindicato patronal é o principal responsável pela condução das atividades do arranjo. O sindicato teve início em 1979, com a participação das grandes empresas, como: Bical, Tiptoe, Ypo, Suzel e Kiuty (Sinbi, 2007).

Os resultados da pesquisa revelam uma importante atuação do Sinbi na coordenação das ações do APLB, conforme as entrevistas com as empresas. Entretanto, nesse projeto participam apenas micro e pequenas empresas montadoras de sapatos. As grandes empresas não participam desse projeto, embora façam parte formalmente e atuem em outros projetos do sindicato.

Em 2006, foi criado um comitê gestor do convênio do APLB, formado por integrantes da governança local e empresários. Esse projeto foi construído focado nas necessidades reais das micro e pequenas empresas, conforme relatou a gestora do comitê: "havia uma demanda das micro e pequenas empresas. Percebíamos como entidade que as pequenas empresas necessitavam de muito apoio". Segundo dados levantados, o sindicato não conseguia atender toda essa demanda das empresas. Para concretizar a proposta, eram necessários grandes parceiros para captar recursos e conhecimentos. Primeiramente, houve uma articulação com o Sebrae. Foram três anos de negociação, desde 2003, até a aprovação do projeto em 2006, articulando entidades locais, estaduais e federais. 
Na primeira etapa do convênio, as micro e pequenas empresas integrantes do APLB receberam consultores para diagnosticar as reais necessidades. O comitê gestor trouxe profissionais do Instituto Brasileiro de tecnologia do Couro, Calçados e Artefatos (Ibtec), professores da Fundação Getulio Vargas (FGV) e consultores do Instituto Europeu de Design (IED). As consultorias, treinamentos e a interação com esses profissionais permitiram elevar a capacitação e a integração entre os empresários, conforme vários relatos. Dados coletados em campo revelam um volume significativo da cooperação entre as empresas participantes.

As metas desse projeto envolvem o aumento de competitividade das empresas; expandir o volume de pares comercializados em 10\%; aumentar a lucratividade em $6 \%$, reduzir os custos de produção em 6\% e expandir a exportação em 4\%. Para atingir os resultados, o comitê gestor desenvolveu parcerias com consultorias e centros de pesquisa para capacitação dos empresários em finanças, produção, marketing e vendas, design e um treinamento chamado "Cooperar para competir".

Os empresários foram capacitados a reduzir o tempo de produção e controlar com eficácia os gastos e os rendimentos do processo de fabricação. Além disso, as empresas foram orientadas a investir em equipamento e tecnologia, buscando melhorias no layout, desempenho da linha de produção e aumento de lucratividade.

Além da importante atuação do sindicato, há a participação de outras instituições, como Senai, Sesi, Sesc, Sest/Senat, Prefeitura Municipal, Governo do Estado de São Paulo, Associação Comercial, Fiesp/Ciesp, Anpei, IPT, IED, Cooperativa de Crédito de Indústria de Birigui, faculdades e instituições financeiras (Sebrae, 2007).

Para facilitar a visualização da interferência dos vários atores na governança do arranjo, o quadro 1 classifica a estrutura de governança do APLB, conforme a coleta de dados realizada com as empresas e instituições.

\section{Quadro 1}

\begin{tabular}{|c|c|c|c|c|}
\hline & Local & Estadual & Nacional & Internacional \\
\hline $\begin{array}{l}\text { Governança } \\
\text { Pública }\end{array}$ & $\begin{array}{l}\text { Prefeitura Municipal de } \\
\text { Birigui }\end{array}$ & $\begin{array}{l}\text { Governo do Estado } \\
\text { de São Paulo }\end{array}$ & $\begin{array}{l}\text { Ministério do } \\
\text { Desenvolvimento, Indústria } \\
\text { e Comércio; Carteira do } \\
\text { Comércio Exterior (Cacex) para } \\
\text { estímulo a exportação; Banco } \\
\text { do Brasil }\end{array}$ & \\
\hline $\begin{array}{l}\text { Governança } \\
\text { Privada }\end{array}$ & $\begin{array}{l}\text { Grandes empresas } \\
\text { têm elevada influência } \\
\text { política no arranjo }\end{array}$ & & FGV & \\
\hline $\begin{array}{l}\text { Governança de } \\
\text { ator coletivo }\end{array}$ & $\begin{array}{l}\text { Sindicato dos Calçados } \\
\text { e Vestuários de Birigui } \\
\text { (Sinbi), Associação } \\
\text { Comercial de Birigui; } \\
\text { Cooperativa de Crédito } \\
\text { de Indústria de Birigui }\end{array}$ & Fiesp/Ciesp & $\begin{array}{l}\text { Sebrae / Senai / Sesi } \\
\text { Assintecal } \\
\text { Anpei } \\
\text { IPT } \\
\text { Ibtec } \\
\text { Francal (feira) } \\
\text { Couromoda (feiras) }\end{array}$ & $\begin{array}{l}\text { Instituto Europeu de } \\
\text { Design (IED); } \\
\text { Banco Interamericano } \\
\text { de Desenvolvimento } \\
\text { (BID) }\end{array}$ \\
\hline
\end{tabular}




\begin{tabular}{|c|c|c|c|c|}
\hline & Local & Estadual & Nacional & Internacional \\
\hline $\begin{array}{l}\text { Governança a } \\
\text { montante }\end{array}$ & $\begin{array}{l}\text { Depende de compra } \\
\text { de matéria-prima }\end{array}$ & $\begin{array}{l}\text { Depende de compra } \\
\text { de matéria-prima }\end{array}$ & $\begin{array}{l}\text { Depende de compra } \\
\text { de matérias-primas e } \\
\text { equipamentos de outros } \\
\text { estados }\end{array}$ & \\
\hline $\begin{array}{l}\text { Governança a } \\
\text { jusante }\end{array}$ & $\begin{array}{l}\text { Distribuição em } \\
\text { shoppings locais }\end{array}$ & $\begin{array}{l}\text { Distribuição em } \\
\text { grande varejo e } \\
\text { criação de marcas } \\
\text { próprias }\end{array}$ & $\begin{array}{l}\text { Distribuição em grande varejo } \\
\text { e criação de marcas próprias. } \\
\text { Foco no Mercado Nacional: } \\
\text { um a cada nove pares no } \\
\text { Brasil é de Birigui }\end{array}$ & $\begin{array}{l}\text { Depende pouco do } \\
\text { mercado externo: } \\
\text { Exportação: 8,2\% }\end{array}$ \\
\hline
\end{tabular}

Fonte: Elaborado pelos autores.

No APLB, a governança é exercida por um ator coletivo, o Sinbi. Nessa governança, há uma diversidade da atuação pública, entidades estaduais, locais e empresas privadas. A prefeitura e o governo do estado têm participação no arranjo. Entretanto, é o sindicato o ator central e exerce a governança de forma legítima e formal. O arranjo de Birigui também recebe apoio de outras entidades, estaduais, nacionais, do Instituto de Design Europeu, e recebeu financiamento do BID.

Em nível da governança pública, o arranjo tem acordo com a Prefeitura Municipal de Birigui, Secretaria Estadual do Governo do Estado de São Paulo e Ministério da Indústria e Comércio. Inclusive, no setor calçadista, devido à forte concorrência dos produtos chineses, o governo aumentou, pela primeira vez nos últimos seis anos, a Tarifa Externa Comum (TEC) de dois produtos (calçados e têxteis) para 35\% do nível máximo imposto pelo Mercosul, informa Dianni (2007). O governo afirma que o objetivo é proteger os setores da concorrência desleal.

Com relação à governança local privada, destaca-se o papel político exercido pelas grandes empresas. Embora essas grandes empresas não participem do projeto coordenado pelo comitê, vários depoimentos revelam que as grandes empresas têm papel importante no direcionamento das ações do projeto via sindicato.

A governança a jusante (distribuição dos produtos) do arranjo envolve a distribuição em shoppings locais e o grande mercado nacional. Há muitas empresas buscando o desenvolvimento e a criação de marcas próprias. Esse é o papel da parceria internacional com o IED, buscar design alinhado com a moda internacional. Vários depoimentos apontam para os esforços coletivos das empresas para a criação de marcas próprias para agregar maior valor ao produto e diminuir o poder dos grandes compradores varejistas. O grande varejo muitas vezes fragiliza a capacidade competitiva das empresas pelo baixo preço pago pelos calçados. Com a criação de marcas próprias, novos materiais, tecnologias, design e cores, a governança exercida pelos grandes compradores nacionais passa a ter menor influência no arranjo.

As empresas perceberam que a capacidade de criar marcas e distribuir seus produtos agrega mais valor e ganhos aos produtores. Muitas empresas têm pulverizado a venda para vários clientes, permitindo reduzir riscos associados à dependência de poucos compradores. 
Também há na cidade o shopping dos calçados responsável em distribuir uma pequena parte para os visitantes e moradores da cidade de Birigui. Um fato interessante é que a Klin, uma das maiores empresas, abriu um shopping separado e individual. Isso reforça a ideia da elevada legitimidade nacional conquistada junto aos clientes por algumas das grandes marcas do arranjo.

As empresas que buscam marcas próprias aproximam-se do conceito de arranjo coordenado pelo produtor (producer driven), conforme apresentado por Gereffi (1999). As empresas que atuam como manufaturas contratadas aproximam-se do conceito de arranjo coordenado pelo comprador (buyer driven). Há uma combinação de empresas buscando marcas fortes e posicionamento no mercado e outras atuando com custo baixo para fornecer para o grande varejo. Para o primeiro grupo de empresas, a vantagem competitiva está na diferenciação e, para as empresas subcontratadas pelos varejistas, está nos volumes e no custo de produção.

\subsection{Governança do arranjo produtivo local de Jaú}

O APLJ iniciou suas atividades de forma coordenada em 2003, com apoio do sindicato patronal (Sindicalçados) e do Sebrae. Conforme revelam os resultados da pesquisa, o sindicato tem elevada participação na articulação dos atores locais. O sindicato é o principal responsável em coordenar as atividades, cursos, palestras, consultorias, entre outras ações. O sindicato é uma organização sem fins lucrativos, fundada em 1979 para apoiar os empresários do setor calçadista da região de Jaú. Conforme declarado em documentos do sindicato, "seu intuito é coordenar, proteger e representar a categoria, além de atuar na defesa das políticas do setor frente aos diferentes níveis de governo executivo e legislativo" (Sindicalçados, 2006).

O programa conduzido pelo sindicato objetiva integrar a cadeia produtiva do calçado e apoiar as empresas na gestão, na produção, na interação com o meio ambiente e na atuação nos mercados coureiro e calçadista. A estrutura formada por lideranças das empresas e das instituições parceiras tem a responsabilidade de atrair investimentos, organizar ações coletivas, treinar e capacitar empresários, gerar oportunidades para melhorar as áreas críticas do setor. Um foco prioritário está no aumento da qualificação da mão de obra e no estabelecimento de estratégias comerciais, mediante realização de feiras e missões técnicas.

Além do Sebrae, outras entidades prestam auxílio, como: Senai, Ciesp, Finep, Fatec, Sesi, Senac, Ufscar, IPT, bancos e sindicatos e Prefeitura Municipal, através de um programa de desenvolvimento sustentável do polo calçadista (Sebrae, 2007). Embora haja elevada participação de instituições, o sindicato patronal tem o papel de coordenar as ações entre empresas e instituições. A governança do APLJ pode ser classificada como governança de ator coletivo, da mesma forma que a do APLB. Nessa governança há uma mescla da atuação pública, entidades estaduais, locais e empresas privadas. O quadro 2 classifica a estrutura de governança do APLJ.

Do ponto de vista comercial, a governança é exercida em grande parte por grandes varejistas armênios com pontos de venda no estado de São Paulo. A explicação para esse caráter 
étnico na distribuição e na confecção dos calçados pode ser explicada pela grande habilidade dos artesãos de Marash com o couro (Grun, 2008). Esse fato conferiu aos armênios, desde o início do século XX, habilidades para atuar no ramo dos calçados em São Paulo. Através de redes étnicas, os armênios buscavam recursos financeiros, estoques de mercadorias junto à comunidade. Aos poucos, a comunidade migra para o comércio de calçados de baixa renda, nesse momento, assumido pelos filhos de imigrantes (segunda e terceira geração). As gerações contemporâneas atuam no ramo da moda, como a Zoomp e Teresa Gureg (Grun, 2008). Isso está de acordo com as análises de Truzzi e Sacomano Neto (2009) sobre o papel das redes étnicas na economia e desenvolvimento regional.

Quadro 2

\begin{tabular}{|c|c|c|c|c|}
\hline & Local & Estadual & Nacional & Internacional \\
\hline $\begin{array}{l}\text { Governança } \\
\text { Pública }\end{array}$ & $\begin{array}{l}\text { Prefeitura Municipal de } \\
\text { Jaú }\end{array}$ & $\begin{array}{l}\text { Secretaria Estadual } \\
\text { Unesp }\end{array}$ & $\begin{array}{l}\text { Ministério da Indústria e } \\
\text { Comércio Exterior } \\
\text { Ufscar } \\
\text { IPT }\end{array}$ & \\
\hline $\begin{array}{l}\text { Governança } \\
\text { Privada }\end{array}$ & $\begin{array}{l}\text { Poucas grandes empresas } \\
\text { com poder político }\end{array}$ & & & \\
\hline $\begin{array}{l}\text { Governança de } \\
\text { ator coletivo }\end{array}$ & $\begin{array}{l}\text { Sindicalçados (sindicato } \\
\text { patronal); Sindicouros }\end{array}$ & $\begin{array}{l}\text { Ciesp, Fiesp, Fatec } \\
\text { Centro São Paulo Design } \\
\text { (CSPD) }\end{array}$ & $\begin{array}{l}\text { Sebrae; Senai/Sesi; } \\
\text { Senac } \\
\text { Assintecal; Finep }\end{array}$ & $\begin{array}{l}\text { Banco Interamericano } \\
\text { de Desenvolvimento } \\
\text { (BID) }\end{array}$ \\
\hline $\begin{array}{l}\text { Governança a } \\
\text { montante }\end{array}$ & $\begin{array}{l}\text { Depende de compra de } \\
\text { matérias-primas }\end{array}$ & $\begin{array}{l}\text { Depende de compra de } \\
\text { matérias-primas }\end{array}$ & $\begin{array}{l}\text { Depende de compra de } \\
\text { matérias-primas }\end{array}$ & \\
\hline $\begin{array}{l}\text { Governança a } \\
\text { jusante }\end{array}$ & $\begin{array}{l}\text { Venda através do } \\
\text { shopping dos calçados }\end{array}$ & $\begin{array}{l}\text { Depende do mercado } \\
\text { paulista e dos } \\
\text { comerciantes armênios } \\
\text { para a distribuição dos } \\
\text { calçados } \\
\text { Venda através do } \\
\text { shopping dos calçados } \\
\text { em outras cidades }\end{array}$ & $\begin{array}{l}\text { Depende da distribuição } \\
\text { em menor escala para o } \\
\text { mercado nacional }\end{array}$ & \\
\hline
\end{tabular}

Fonte: Elaborado pelos autores.

O desenvolvimento dos armênios no negócio calçadista influencia sobremaneira as empresas da região de Jaú. Muitas empresas da região fazem a produção como manufatura contratada, sem marcas próprias. Por muitos anos, as empresas do APLJ vendiam seus produtos com marcas desses grandes varejos. Entretanto, os resultados da pesquisa revelam um esforço das empresas em buscar desenvolver suas marcas próprias e de certa forma exercer maior poder de negociação com grandes compradores. Essas são as relações de poder não locais indicadas por Suzigan, Garcia e Furtado (2002). Mesmo os atores externos ao sistema local têm relações de comando em determinados sistema produtivos, como ocorre no ramo dos calçados femininos. 
A busca pelas marcas próprias e alternativas de distribuição dos calçados através de "shoppings dos calçados" mostra uma mobilização dos empresários no sentido de busca de ganhos na distribuição e comercialização dos calçados. Atualmente são três shoppings com venda direta ao consumidor final. O esforço coletivo das instituições locais e dos empresários é tornar a governança comercial menos vulnerável a poucos canais de distribuição e mais preparada para atuar em outros mercados, com maior agregação de valor através da moda.

No APLJ há uma mescla na governança comercial entre empresas dirigidas pelo produtor (producer-driven), aquelas que criam marcas próprias através de estilo e investimento em moda e as empresas dirigidas pelo comprador (buyer driven), ou seja, aquelas em que o preço é determinado pelo grande varejo, o produtor tem pouco poder de barganha e o calçado é uma commodity.

Não foi destacada uma empresa do APL capaz de liderar a governança local, como ocorre no APLB. Atualmente, são 1.182 estabelecimentos formais (Sindicalçados, 2006) formando uma rede gigantesca de relacionamentos comerciais. Desse número, 800 empresas são bancas de prestação de serviços, muitas vezes atuando informalmente. Pelos dados da Rais/Caged de 2006, produtores de calçados, produtores de máquinas e equipamentos e comercialização são 461 empresas, representando a cadeia calçadista 13,59\% da economia regional.

Jaú então apresenta uma densidade elevada de empresas participantes da cadeia calçadista. Essa estrutura produtiva do APLJ é altamente flexível do ponto de vista do mix de produtos, uma vez que a moda feminina é internacionalmente modificada a cada estação. Essa desintegração vertical exige a manutenção de interação constante entre os atores, conforme propõem Suzigan, Garcia e Furtado (2002). Conforme classificação apresentada por Storper e Harrison (1991), o APLJ está mais próximo do modelo core-ring with coordinating firm. Não há liderança de algumas poucas empresas e sim de um conjunto de empresas. As empresas montadoras de calçados acabam exercendo uma forte governança nos fornecedores e principalmente nas pequenas bancas de pesponto.

\subsection{Governança do arranjo produtivo local de Piracicaba}

O Apla iniciou sua atividade no ano de 2006. A Secretaria de Indústria e Comércio de Piracicaba (Semic) teve papel significativo no lançamento e coordenação das ações do Apla em sua origem. Com essa secretaria, sob liderança de Luciano Tavares Almeida, concebeu-se o projeto, a execução e a coordenação das primeiras atividades do arranjo.

O Apla é "uma entidade que agrega toda a cadeia produtiva do álcool formada por indústrias produtoras de equipamentos, centros de pesquisa e desenvolvimento tecnológico, associações voltadas ao setor alcooleiro e produtores de álcool" e visa facilitar a interação dos integrantes buscando gerar maior valor às cadeias produtivas de combustíveis renováveis (Apla, 2006). A competência do Apla envolve o projeto, a produção, a comercialização de máquinas e equipamentos para a geração de biocombustíveis. 
No dia 25 de setembro de 2007, oficializou-se a nova diretoria executiva do Apla, juntamente com seu conselho estratégico (inclusive com CNPJ próprio). Segundo o próprio secretário da Indústria e Comércio, o sr. Luciano Tavares de Almeida, essa mudança teve como principal razão: 1) permitir a atuação de forma jurídica e demonstrar a seus associados a estrutura de caixa e o controle econômico-financeiro e contábil e 2) a coordenação do arranjo passa a ser gradativamente desvinculada do poder público, para uma forma de governança local privada, como também apontado por Suzigan, Garcia e Furtado (2002).

No caso específico do Apla de Piracicaba, identificou-se a existência de duas formas de governança exercidas em momentos distintos. Num primeiro momento, as ações eram coordenadas diretamente pelo poder público através da Semic, até atingir o instante da oficialização de sua diretoria. A partir desse momento, predomina característica de governança local privada, com grande participação do apoio público e instituições. O arranjo institucionalizou-se à medida que articulou os membros e elegeu normas, regras, acordos com outras organizações e instituições locais, nacionais e internacionais, conforme análise apresentada por Noronha e Turchi (2005). A governança do arranjo, embora tenha como o presidente executivo ainda uma figura pública, constitui-se por uma instituição formalmente estabelecida, possuidora de CNPJ e regida por um estatuto devidamente registrado em cartório, cuja formação do corpo diretor é de dirigentes de empresas que atuam na cadeia produtiva do álcool de Piracicaba.

Outro aspecto identificado na pesquisa é a forte evidência do apoio do poder público nas ações do Apla. Esse fato pode ser evidenciado pelos resultados obtidos nas entrevistas às empresas. Todas as empresas pesquisadas afirmaram o apoio da Semic da Prefeitura Municipal de Piracicaba. Nesse sentido, a despeito de serem exemplos de governança local privada, é possível observar o apoio de setor público nesse processo. O quadro 3 classifica a estrutura de governança do Apla.

Quadro 3

\begin{tabular}{|c|c|c|c|c|}
\hline & Local & Estadual & Nacional & Internacional \\
\hline $\begin{array}{l}\text { Governança } \\
\text { pública }\end{array}$ & $\begin{array}{l}\text { Prefeitura Municipal de Piracicaba; } \\
\text { Secretaria da Indústria e } \\
\text { Comércio (Semic) }\end{array}$ & Esalq/USP & $\begin{array}{l}\text { Ministério do } \\
\text { Desenvolvimento } \\
\text { Apex; Banco do } \\
\text { Brasil }\end{array}$ & \\
\hline $\begin{array}{l}\text { Governança } \\
\text { Privada }\end{array}$ & $\begin{array}{l}\text { Grandes empresas como a } \\
\text { Dedini (metal mecânico) e Cosan } \\
\text { (Usina) }\end{array}$ & Unimep & & $\begin{array}{l}\text { Grandes investidores } \\
\text { adquirindo usinas } \\
\text { nacionais }\end{array}$ \\
\hline $\begin{array}{l}\text { Governança de } \\
\text { ator coletivo }\end{array}$ & $\begin{array}{l}\text { Simesp; Acipi; Aderp; Copervap; } \\
\text { Simtec } \\
\text { Centro de Tecnologia Canavieira } \\
\text { (CTC); Piracicaba 2010; } \\
\text { Fumep }\end{array}$ & $\begin{array}{l}\text { Coplacana } \\
\text { Fiesp }\end{array}$ & $\begin{array}{l}\text { Polo Nacional de } \\
\text { Biocombustíveis } \\
\text { Senai } \\
\text { CTC } \\
\text { Inmetro } \\
\text { Apex }\end{array}$ & $\begin{array}{l}\text { Organização Mundial do } \\
\text { Comércio (OMC) }\end{array}$ \\
\hline
\end{tabular}

Continua 


\begin{tabular}{|c|c|c|c|c|}
\hline & Local & Estadual & Nacional & Internacional \\
\hline $\begin{array}{l}\text { Governança a } \\
\text { montante }\end{array}$ & $\begin{array}{l}\text { Reúne os principais fornecedores } \\
\text { de tecnologia canavieira }\end{array}$ & $\begin{array}{l}\text { O estado de São } \\
\text { Paulo, como } \\
\text { maior produtor } \\
\text { do Brasil, } \\
\text { oferece boa } \\
\text { disponibilidade } \\
\text { de tecnologias e } \\
\text { insumos }\end{array}$ & & \\
\hline $\begin{array}{l}\text { Governança a } \\
\text { jusante }\end{array}$ & & & $\begin{array}{l}\text { Venda para o } \\
\text { mercado nacional }\end{array}$ & $\begin{array}{l}\text { Venda de etanol no } \\
\text { mercado externo. } \\
\text { Depende da aceitação } \\
\text { nos mercados } \\
\text { internacionais. }\end{array}$ \\
\hline
\end{tabular}

Fonte: Elaborado pelos autores.

Parte significativa das atividades do Apla envolve o mercado internacional, inclusive a cooperação das empresas está muito associada a essa atividade. Foram realizadas diversas viagens internacionais com o objetivo de divulgar a capacidade da região de Piracicaba de prover etanol e a tecnologia para a produção. O Apla também firmou convênio com a Agência de Promoção de Exportações e Investimentos (Apex) com um valor estimado de investimento de R \$ 4,5 milhões em 2007 e 2008. Esse investimento visa realizar missões internacionais a países com potencial de importações de etanol, de bens de capital, serviços de engenharia e de tecnologias geradas nos institutos de pesquisa.

O Apla tem uma coordenação voltada a atender o mercado internacional de Etanol. Embora a governança local seja dirigida claramente pelos produtores de etanol (usinas) e também por grandes empresas metal-mecânica. O Apla é evidentemente um sistema dirigido pelo produtor (producen driven), conforme denominação de Storper e Harrison (1991). Alguns entrevistados mencionaram o elevado poder das empresas de grande porte, como Dedini, Case e Mantoni. Confirma a proposição de Storper e Harrison (1991) ao aproximar-se das cadeias dirigidas pelo produtor (producer-driven), em especial nas indústrias metal-mecânica, eletrônica e química.

Embora haja evidências de que a cadeia sucroalcooleira seja dirigida pelo produtor (producer-driven), o mercado internacional evidenciou a necessidade de padronização (mundial) do etanol, a fim de que não haja nenhum tipo de empecilho técnico nas negociações desse produto para o mercado global. Então, o Apla, em conjunto com o Inmetro, está desenvolvendo um selo socioambiental, garantindo assim um padrão internacional de qualidade para o etanol. Com a procura mundial de combustíveis renováveis, o Apla tem se projetado internacionalmente através de parcerias e visitas internacionais. O fato de o Apla ter forte direção a projetos de internacionalização está de acordo com as formulações de Gereffi (1999) com relação ao papel dos compradores globais presentes em alguns sistemas produtivos. Hoje o etanol é um exemplo claro, haja vista o esforço das entidades brasileiras 
em sustentar o etanol como uma fonte limpa, renovável e que não afeta a produção e os preços dos alimentos.

Evidentemente, essa ocorrência se dá em função da condição favorável da indústria sucroalcooleira brasileira diante do mercado global. Segundo Salomão e Onaga (2006), o etanol virou a principal estrela do mercado energético global, e nenhuma economia no mundo tem tanto a ganhar como a do Brasil. Nos últimos anos, uma forte escalada no preço do petróleo, principal produto da matriz energética global, tem levado o mundo a buscar alternativas.

Nesse sentido, pode-se traçar um paralelo bastante interessante dos resultados com os estudos realizados por Suzigan, Garcia e Furtado (2002). Os autores defendem a ideia de que a forma de liderança exerce grande influência sobre as ações e os benefícios inerentes ao arranjo produtivo local. Os atores do arranjo, portanto, aceitam e passam a adaptar-se à estrutura de governança presente nessa relação, podendo ser originada pelo grau de hierarquia, liderança e comando (ou, alternativamente, colaboração e cooperação) exercidos por uma empresa ou entidade ou mesmo grupo.

Percebe-se, portanto, que as possibilidades de desenvolvimento dos APLs dependem em grande parte das formas de governança, pública ou privada, do sistema articuladas com grande interesse internacional.

\section{Análise comparativa da governança nos arranjos}

A forma de governança dos arranjos produtivos locais é heterogênea e complexa. Determinados arranjos podem ter um fornecedor único em algum item, conferindo maior poder e dependência desse fornecedor. Ou um arranjo pode ter distribuidores influentes e com poder de compra das empresas, por deterem os canais de distribuição. Além do caráter local, outros atores não localizados geograficamente no arranjo podem exercer a coordenação no sistema. Como ocorre na distribuição dos calçados do APLJ, onde os armênios, donos de comércios de calçados do estado de São Paulo, dominam parcela significativa dos canais de distribuição. Para dar conta de descrever e entender essa amplitude de influências nas formas de coordenação foi apresentada a matriz da governança de cada arranjo.

Os resultados da pesquisa revelam o importante papel tributado às políticas públicas e institucionais para apoio dos arranjos (local, estadual e nacional). Nos três APLs pesquisados há uma entidade central na coordenação do arranjo, originada pela ação coletiva das empresas privadas e apoiada pelo setor público. Isso confere ao poder público capacidade de articular e aglutinar atores em torno de objetivos comuns, como ocorreu no Apla.

Segundo Suzigan, Garcia e Furtado (2002), a governança local exercida pelo poder público proporciona ações voltadas para a assistência e a promoção dos produtores aglomerados. Entre tais ações, destacam-se as que promovem o desenvolvimento e a capacitação dos agentes internos do arranjo, formando parcerias com centro de treinamento e capacitação de mão de obra, centro de prestações de serviços tecnológicos, agências governamentais de desenvolvimento. Diversos estudos de casos destacam a importância do apoio do setor público local, atuando como suporte às atividades de apoio e de prestação de serviços ao setor produtivo. 
No APLB e APLJ a governança está atrelada ao papel do sindicato patronal (governança de ator coletivo). Nesses arranjos, esses são os atores com maior grau de importância para a coordenação das atividades, parcerias e a própria "estratégia” para o arranjo. No Apla há um primeiro momento de grande apoio do poder público, até culminar em uma governança de ator coletivo, formalmente independente do poder público. No Apla a governança pública teve maior importância para a formação de desenvolvimento do arranjo.

O contexto do surgimento e evolução dos arranjos está de acordo com as formulações de Storper e Harrison (1991) e Humphrey e Schimtz (2000). Os autores evidenciam o papel da governança pública e privada para o desenvolvimento dos APLs. Também está de acordo com as proposições de Suzigan, Garcia e Furtado (2002) sobre o papel da governança para o estímulo da atividade inovativa e melhoria da competitividade das empresas, sustentada pela capacidade de aprendizagem e criação de competências, conforme mencionam Lastres e Cassiolato (2005).

A governança privada está relacionada com a capacidade de as grandes empresas influenciarem os arranjos, principalmente no APLB e no Apla. No Apla, a Cosan (maior usina do mundo em moagem de cana) e a Dedini representam lideranças nacionais e internacionais na produção de álcool de açúcar e máquinas e equipamento, respectivamente. Conforme dados coletados, a Dedini tem participado ativamente das iniciativas do arranjo. Isso pode ser explicado pelo amplo mercado para fornecimento de tecnologia alcooleira presente hoje.

Em Birigui há grandes empresas também associadas ao sindicato que de alguma forma exercem influência no arranjo. Algumas dessas empresas são a Klin, Papilli, Tiptoe, Kidy e Bibi, conforme relatado em Graça (2007). As grandes empresas criam assimetrias locais e capacidade de liderança de algumas empresas.

A ideia de entender o arranjo através das relações de poder está de acordo com as formulações de Storper e Harrison (1991). Os autores entendem a governança a partir das relações de poder, onde atores mais ou menos centrais ocupam posições de comando e/ou coordenação no arranjo. Esse ponto também é destacado por Cassiolatto e Szapiro (2002) e Suzigan, Garcia e Furtado (2002). Os autores destacam o papel das empresas líderes na governança, onde as relações podem configurar-se com "fortes" hierarquias devido ao diferenciado poder de negociação dos atores.

A governança a montante e a jusante está relacionada com a capacidade de fornecedores ou clientes coordenarem o sistema, conforme observado por Gereffi (1999) nas cadeias coordenadas pelo produtor (producen-driven) e nas cadeias coordenadas pelo comprador (buyer-driven). Essas duas formas de governança, jusante e montante, buscam captar o nível de interferência dos fornecedores e distribuidores no arranjo e as relações assimétricas existentes no contexto das relações comerciais.

Similarmente no APLJ e APLB as empresas têm desenvolvido marcas próprias e diversificado seus canais de distribuição. Isso é uma forma de diminuir a dependência de um canal de venda. Os arranjos calçadistas são tipicamente coordenados pelo comprador (buyer driven), na maioria, grandes varejos como C\&A, Pernambucanas, Renner.

O grau maior ou menor de controle de preços e as condições de negociação dependem da posição das empresas na cadeia produtiva (Sacomano Neto e Truzzi, 2009). Para as empresas que vendem apenas para grandes varejos, representam um elevado risco pelo grau de 
dependência. Várias empresas de ambos os arranjos mencionaram a busca de novos clientes e a relação predatória existente entre as empresas produtoras e os grandes varejistas. No APLB a dependência da governança a jusante situa-se em um contexto nacional e, no APLJ, em um contexto estadual. Esses varejos impõem preços muito abaixo do mercado, além de dificultar a consolidação de marcas próprias, exercendo forte poder de coordenação a jusante dessas empresas.

No APLB, uma empresa das pesquisadas vende para um grande varejista. A empresa apresenta elevada capacidade produtiva para ganhar vantagens no volume de produção. A mesma empresa também dispõe de marca própria e busca pulverizar a distribuição dos calçados. Essa forma de pulverizar as vendas está de acordo com os estudos de Uzzi (1997) para reduzir dependências de um conjunto único de atores. Ao produzir para o grande varejo, consegue contratos de longo prazo e grandes volumes de produção. Ao produzir uma marca própria, passa a produzir em menor volume, mas incorpora novos modelos e materiais para inserir a marca no mercado, já que os APLs calçadistas têm muita influência da moda.

Em todos os arranjos as estruturas de governança variam conforme o tipo de sistema produtivo e as relações de poder. O resultado está de acordo com as afirmações de Suzigan, Garcia e Furtado (2002), ao destacarem que os sistemas produtivos variam conforme a estrutura de coordenação, as interações verticais e horizontais na cadeia e o ambiente institucional, o que foi também observado por Noronha e Turchi (2005). Com base em Storper e Harrison (1991), a figura seguinte classifica o tipo de estrutura de governança dos arranjos, com base nesses critérios.

Figura

Tipo de estrutura de governança dos arranjos

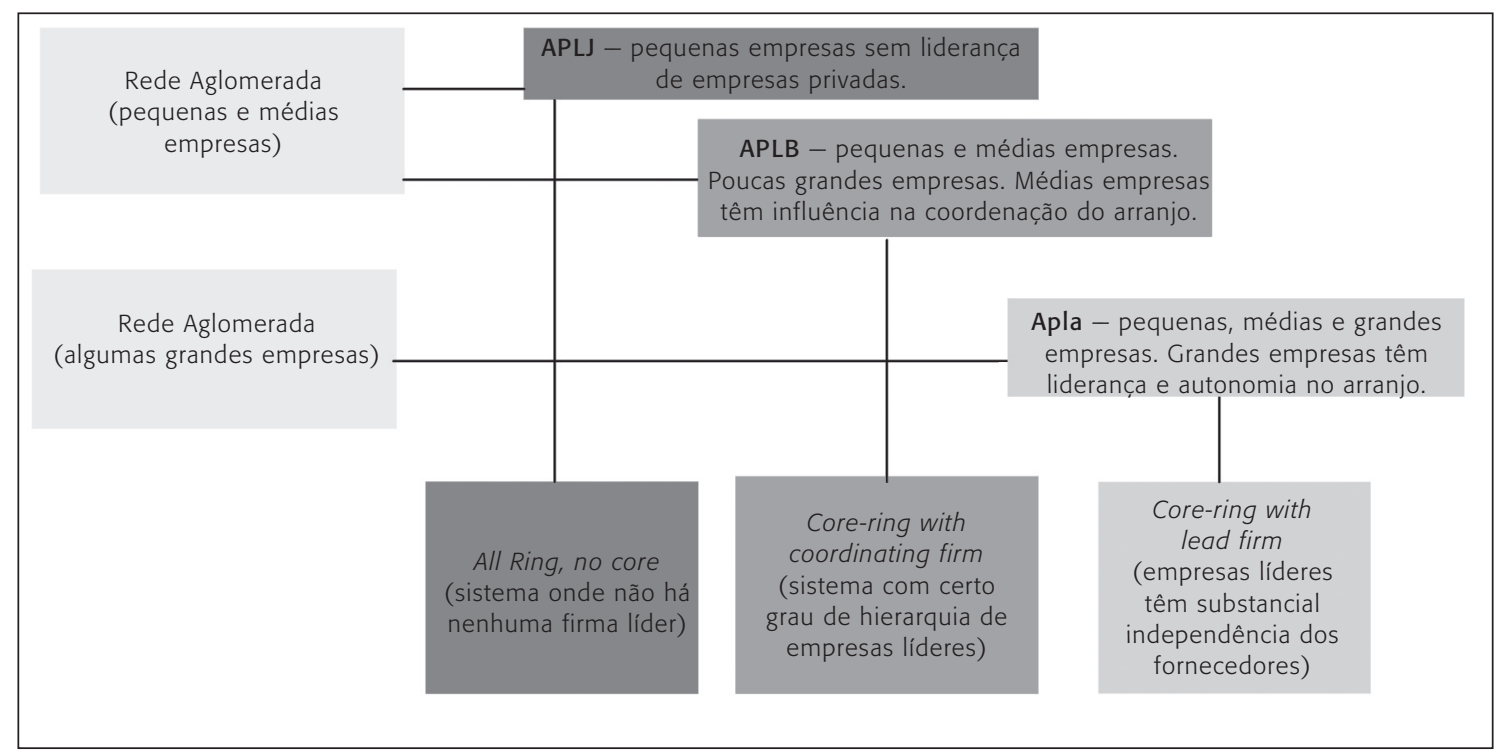

Fonte: Elaborado pelos autores. 
Os arranjos estudados foram classificados a partir do modelo apresentado do Storper e Harrison (1991). Os autores destacam que todo sistema produtivo tem uma estrutura de insumo e produto (conjunto de unidade de produção de diferentes tamanhos e ligadas entre si), uma estrutura de governança (autoridade e poder) e territorialidade do arranjo (disperso ou concentrado).

No sentido horizontal da figura apresentam-se os tipos de estrutura de governança e, no sentido vertical, a estrutura de insumos e produtos do sistema. O APLJ tem grande número de pequenas empresas com poucas grandes empresas exercendo a coordenação. No APLB há grandes empresas com interferência na governança do sistema. Nos arranjos calçadistas (APLJ e APLB), o grau de aglomeração e territorialidade dos arranjos é mais elevado. No Apla as empresas estão territorialmente mais dispersas, com a presença de grandes empresas, com capacidade de coordenação. Esses aspectos chamam a atenção para o papel da aglomeração territorial para o desenvolvimento econômico de uma determinada região, conforme mencionam Storper e Harrison (1991).

Como destacam Lastres e Cassiolato (2005) a competitividade das firmas, além de sua conduta individual, depende de variáveis macroeconômicas, político-institucionais e sociais de infraestrutura. Conforme mencionam os autores, o aproveitamento de ganhos coletivos gerado pela interação entre as empresas, envolvendo cooperação e processos de aprendizagem, é determinante para a competitividade dinâmica e sustentada das empresas.

\section{Considerações finais}

As governanças em APLs podem ser entendidas por mecanismos de comando, intervenção, influência e participação dos atores envolvidos. Para o estudo de um arranjo produtivo local, o mercado deve ser compreendido a partir de um conjunto de elementos locais, relacionais, culturais e também por diferentes regimes de regulação do Estado, com o envolvimento de atores locais e um maior ou menor grau de institucionalização, de flexibilidade, de abertura e de influências externas (Steiner, 2006; Powell, 1990; Paulillo, 2000). Apesar de variar conforme o tipo do arranjo produtivo local, Suzigan, Garcia e Furtado (2002) afirmam que a governança passa a ser o mecanismo fundamental para o fomento da atividade inovativa, dado tratar-se de um processo intrinsecamente social, coletivo e interdependente entre os agentes (processo de aprendizado causado pela difusão do conhecimento). Tais ações têm como alicerce um sistema de coordenação desenvolvido e implantado e capaz de aglutinar esforços para trazer benefícios e vantagens competitivas aos atores participantes dos arranjos.

O desenvolvimento desses arranjos depende da articulação entre atores públicos e privados, capazes de promover a governança no sentido de aglomerar e incentivar os ganhos coletivos aos atores participantes no espaço geográfico. Entretanto, a complexidade presente em um dado espaço econômico foi destacada por François Perroux (citado por Ferreira, 1989). O autor considera os espaços econômicos constituídos por um conjunto de relações que se referem aos amplos fenômenos econômicos, sociais, institucionais e políticos interdependentes, e 
esses espaços são de inúmeras dimensões, de forma que os pontos nesse espaços não podem ser localizados geograficamente. Como afirmado por Lanna (1987), o espaço regional apresenta densidade, dimensão e significado histórico. A dimensão histórico-institucional de cada arranjo torna a articulação entre os atores ainda mais complexa.

A compreensão da interferência desses elementos pode facilitar a atribuição e o desenvolvimento de políticas públicas para as aglomerações de empresas. Inclusive, conforme mencionam Lastres e Cassiolato (2005:17), "mais recentemente, as novas políticas industriais têm se concentrado não mais na firma ou no setor isoladamente, mas sim em blocos agregados de atores em sistemas produtivos, muitas vezes enfatizando a sua dimensão espacial".

Esse fato justifica a importância do tema aqui proposto de analisar e identificar dois níveis distintos de governança nos arranjos produtivos pesquisados: 1) estruturas de governança de atores coletivos podem criar sinergias entre empresas e instituições e promover a difusão do conhecimento e ganhos coletivos para o arranjo; e 2) atores poderosos detentores da coordenação nesses arranjos determinam as relações, os recursos e as regras, propondo novas ordens institucionais. O primeiro nível relaciona-se com a capacidade de os atores coletivos gerarem ganhos para um conjunto de empresas e o segundo nível com as relações de poder e subordinação presentes nas relações do arranjo. Esses pontos são amplamente discutidos nos itens anteriores, quanto ao papel dos atores coletivos e das grandes empresas na interferência da governança dos arranjos.

A governança foi o mecanismo fundamental para o estímulo da troca de recursos e cooperação produtiva e inovativa nos arranjos pesquisados. Entretanto, isso não quer dizer que não existam relações de poder e comando implícitas, como apontado por Gereffi (1999) e Suzigan, Garcia e Furtado (2002). Por esse fato, optou-se em criar categorias de estruturas de governança como: 1) governança pública; 2) governança privada; 3) governança de ator coletivo; 4) governança a montante; e 5) governança a jusante.

No Apla houve maior interferência do poder público para aglutinar os atores em torno do projeto, até sua formalização. No Apla, a Semic da Prefeitura Municipal de Piracicaba exerceu importante papel para o surgimento e a consolidação do arranjo. No APLJ e APLB, os atores de elevada representação figuram nos sindicatos patronais, onde o poder público teve menor interferência. As políticas públicas no nível estadual e federal têm sido importantes para o estímulo dos arranjos e fornecem diretrizes para as instituições locais.

No APLB e Apla há maior interferência das grandes empresas no arranjo, entendida como a governança privada. As grandes empresas têm representação política, participação nas decisões e dominam parte significativa da divisão do trabalho entre as pequenas empresas. Na governança a jusante há maior dependência das empresas APLJ e APLB com os distribuidores de calçados. Esses atores têm grande interferência no que, como e quando produzir. Os arranjos calçadistas são arranjos tipicamente buyer-driven, onde o comprador exerce muita influência no sistema. O Apla caracteriza-se por um arranjo tipicamente producer-driven, onde o produtor tem grande poder. Embora haja essa classificação, nos arranjos calçadistas vários empresários buscam inserir marcas próprias no varejo. Isso favorece o poder de barganha dos produtores e reduz a interferência de grandes varejos. 
O Apla tem maiores problemas institucionais com a abertura de mercados mundiais para a compra do etanol. Esse conjunto de atores influencia na dinâmica e no desenvolvimento desses arranjos. O fato de os Estados Unidos produzirem o etanol à base de milho põe o Brasil em uma situação desfavorável para exportações de grandes volumes de etanol da cana para a Europa. Esses grandes mercados alegam que o etanol brasileiro é insustentável do ponto de vista ambiental e trabalhista. O fracasso da Rodada de Doha, em julho de 2008 em Genebra, prejudica a posição brasileira, pois manterá travada a negociação sobre as quedas das barreiras do álcool nos países ricos. Esses aspectos globais estão no cerne das preocupações dos atores do Apla, os quais se articulam para a criação de um selo socioambiental para o etanol.

O resultado da pesquisa revela o importante papel das entidades públicas e dos sindicatos patronais em estimular um APL. Também ficaram evidentes as interferências das grandes empresas, localmente ou não, nas empresas dos APLs pesquisados. Essas dimensões permitem a compressão da governança a partir de diferentes formas de intervenção e/ou estímulo dos arranjos. Nesse caso, a articulação entre os tipos de governança é vital para o desenvolvimento dos arranjos, isto é, os tipos de governança são interdependentes. No caso do Apla, ocorre um forte incentivo do Estado; já no APLB e no APLJ o sindicato tem maior incentivo do que o Estado. Esse ponto chama a atenção para a necessidade de articulação e maior interdependência entre esses tipos de governança, envolvendo Estado, empresas, entidades de ensino, sindicatos, trabalhadores e sociedade.

As limitações da pesquisa permeiam a amostragem relativamente pequena em cada arranjo. Foram pesquisadas 10 empresas no APLB, 10 empresas no APLJ e 11 empresas no Apla. Com essa amostragem não se pode fazer inferências sobre a população dos arranjos. Entretanto, o esforço de entendimento de cada arranjo e suas relações com outros arranjos aponta para atores mais ou menos representativos na governança do arranjo. $\mathrm{O}$ fato de os arranjos serem heterogêneos quanto à história e à formação limita a comparação entre os sistemas. De qualquer forma, há questões interessantes nessa heterogeneidade; por exemplo, no Apla e no APLB há maior participação de grandes empresas no arranjo.

Pesquisas futuras sobre o tema aqui proposto são profícuas, tanto do ponto de vista acadêmico como prático para o desenvolvimento dos arranjos e de políticas públicas associadas, como:

— o estudo da estrutura e das relações do arranjo, através de medidas quantitativas de análise de redes sociais. As medidas podem refletir posições privilegiadas de atores individuais e a estrutura geral de relacionamento do arranjo.

— o estudo do adensamento dos arranjos também é um tema de grande relevância. Quando um arranjo adensa-se, há maiores possibilidades de troca de recursos e informações.

- o estudo do conjunto de empresas informais atuantes no arranjo, principalmente calçadistas. Estudar quais as razões e os impactos das empresas informais e suas estratégias de inserção no sistema.

— o estudo das relações de cooperação e confiança entre as empresas e instituições. Estudar a relação entre o desenvolvimento da confiança e das trocas no arranjo. 
— o estudo da relação entre as políticas públicas e o desenvolvimento do arranjo.

- o estudo do papel institucional e do Estado no desenvolvimento e no sucesso dos arranjos.

A extensão dos benefícios da aglomeração, além dos seus ganhos coletivos, depende da existência de formas de governança do sistema produtivo local que incentivem a manutenção de relações cooperativas entre os agentes, levando ao estabelecimento de ações conjuntas e ao incremento da inovação e da competitividade do conjunto dos produtos. Distante de encerrar esse debate, novas pesquisas são necessárias para o entendimento integrado da governança e suas intersecções.

\section{Referências}

AMATO NETO, João. Redes de cooperação e clusters competitivos. São Paulo: Atlas, 2000.

APLA. Arranjo Produtivo Local do Álcool de Piracicaba. Disponível em: <www.piracicaba.sp.gov.br> . Acesso em: 11 ago. 2006.

BARROSO, Janayna A.; SOARES, Alexandre A.C. O impacto das políticas públicas no desenvolvimento de arranjos produtivos locais: o caso do APL de ovinocaprinocultura em Quixadá, Ceará. Revista de Administração Pública, Rio de Janeiro, v. 43, n. 6, p. 1435-1457, nov./dez. 2009.

BRITO, Eliane P.Z. et al. A relação entre aglomeração produtiva e crescimento: a aplicação de um modelo multinível ao setor industrial paulista. Revista de Administração Contemporânea, v.14, n. 4, p. 615-632, ago. 2010.

BRITTO, Jorge. Redes de cooperação entre empresas. In: KUPFER, David. Economia industrial: fundamentos teóricos e práticos no Brasil. Rio de Janeiro: Campus, p. 345-388, 2002.

CASSIOLATO, João E.; SZAPIRO, Marina. Arranjos e sistemas produtivos e inovativos locais no Brasil (relatório de pesquisa). Rio de Janeiro: IE/UFRJ, 2002. Disponível em: <www.ie.ufrj.br/redesist>. Acesso em: 20 mar. 2006.

CERVO, Amado L.; BERVIAN, Pedro A.; DA SILVA, Roberto. Metodologia científica. São Paulo: Pearson Prentice Hall, 2007.

CHIOCHETTA, João C. Uma modelagem para implementação de um APL — Arranjo Produtivo Local: o caso do setor metal mecânico da Região Sudoeste do Estado do Paraná. Dissertação (mestrado)

— Centro Federal de Educação Tecnológica, Ponta Grossa, 2005.

COLLINS, Jill; HUSSEY, Roger. Pesquisa em administração. Porto Alegre: Bookman, 2005.

DIANNI, Claúdia. Governo protege calçado e indústria têxtil. Folha de S.Paulo, 26 abr. 2007. Caderno Dinheiro, p. B1.

FERREIRA, Carlos M.C. Espaço, regiões e economia regional. In: HADDAD, P.R. Economia regional: teorias e métodos de análise. Fortaleza: BNB/Etene, 1989. 
GARCIA, Renato; MOTTA, Flávia G.; AMATO NETO, João. Uma análise das características da estrutura de governança em sistemas locais de produção e suas relações com a cadeia global. Gestão de Produção, v. 11, n. 3, p. 343-354, 2004.

GEREFFI, Gary. International trade and industrial upgrading in the apparel commodity chain. Journal of International Economics, v. 48, n. 1, p. 37-70, 1999.

GRAÇA, Carlos A. Governança e inovação tecnológica em APLs: um estudo de caso no APL calçadista de Birigui (SP) — (1990-2000). Tese (doutorado em engenharia de produção) — Escola Politécnica, Universidade de São Paulo, 2007.

GRUN, Roberto. Negócios e famílias em São Paulo. Resenha do livro Sobre a história dos armênios. Disponível em: <www.etni-cidade.net/negocios_familia.htm>. Acesso em: 20 jun. 2008.

HUMPHREY, John; SCHMITZ, Hubert. Governance and upgrading: linking industrial cluster and global value chain research. Brighton: University of Sussex, 2000. (IDS Working Paper 120 - Institute of Development Studies).

LANNA, Ana L. Minas e São Paulo: uma análise comparada. In: GEBARA, Ademir. História regional: uma discussão. Campinas: Unicamp, 1987.

LASTRES, Helena M.M.; CASSIOLATO, João E. Mobilizando conhecimentos para desenvolver arranjos e sistemas produtivos e inovativos locais de micro e pequenas empresas no Brasil. RedeSist, 2005. Disponível em: <www.ie.ufrj/redesist>. Acesso em: 20 nov. 2005.

MARSHALL, Alfred. Princípios de economia. São Paulo: Nova Cultural, 1988.

MENARD, Claude. The economics of hybrid organizations. Journal of Institutional and Theoretical Economics, v. 160, p. 345-376, 2004.

MILANEZ, Bruno; PUPPIM, José A. Ambiente, pessoas e labor: APLs além do desenvolvimento econômico na mineração de opalas em Pedro II, no Piauí. Cad. EBAPE.BR, v. 7, n. 4, p. 527-546, dez. 2009.

NORONHA, Eduardo G.; TURCHI, Lenita. Política industrial e ambiente institucional na análise de arranjo produtivo local. Brasília: Ipea 2005. 31 p. (Texto para discussão no 1.076 .) Disponível em: <www.ipea.gov/publicações/textoparadiscussão>. Acesso em: 23 fev. 2007.

PAULILLO, Luiz. F.O. Redes de poder e territórios produtivos. São Carlos: Rima/Edufscar, 2000.

POWELL, Walter W. Neither market nor hierarchy: network forms of organizations. Research in Organizational Behavior, v. 12, p. 295-336, 1990.

SACOMANO NETO, Mário; TRUZZI, Oswaldo. M.S. Posicionamento estrutural e relacional em redes de empresas: uma análise do consórcio modular da indústria automobilística. Gestão \& Produção, v. 16, p. A132, 2009.

SALOMÃO, Alexa; ONAGA, Marcelo. Etanol o mundo quer. O Brasil tem. Revista Exame, São Paulo, p. 18-23, 2006.

SEBRAE. Serviço Brasileiro de Apoio às Micro e Pequenas Empresas. Disponível em: <www.sebrae. com.br>. Acesso em: 20 set. 2007. 
SINBI. Sindicato da Indústria de Calçados e Vestuário de Birigui. Disponível em: <www.sindicato. org.br >. Acesso em: 24 abr. 2007.

SINDICALÇADOS. Sindicato de Calçados de Jaú. Disponível em: <www.sindicaljau.com.br/index. php?grupo=agenda $>$. Acesso em: 20 mar. 2006.

SOUZA, Sebastião D.C.; ARICA, José. Mudança tecnológica e estratificação competitiva em um arranjo produtivo do setor ceramista. Revista Produção, v. 16, n. 1, p. 88-99, 2006.

STEINER, Philippe. A sociologia econômica. São Paulo: Atlas, 2006.

STORPER, Michael; HARRISON, Bennett. Flexibility, hierarchy and regional developments: the changing structure of industrial production systems and their forms of governance in the 1990s. Research Policy, North-Holland, v. 20, n. 5, p. 407-422, 1991.

SUZIGAN, Wilson; GARCIA, Renato; FURTADO, João. Governança de sistemas de MPMES em clusters Industriais. In: POLÍTICAS PARA SISTEMAS PRODUTIVOS LOCAIS DE MPMES, 2002, Rio de Janeiro. Anais...

SVENSSON, Birgitta; NORDIN, Sara; FLAGESTAD, Arvid. A governance perspective on destination development: exploring partnerships, clusters and innovation systems, Tourism Review, v. 60, n. 2, p. 32-37, 2005.

TAPIA, Jorge R.B. Desenvolvimento local, concertação social e governança: a experiência dos pactos territoriais na Itália. Perspectiva, São Paulo, v. 19, n. 1, p. 132-139, mar. 2005.

TRUZZI, Oswaldo M.S.; SACOMANO NETO, Mário. Economia e empreendedorismo étnico: balanço histórico da experiência paulista. In: MARTES, Ana C.B. (Org.). Redes e sociologia econômica. São Carlos: Edufscar, 2009. v. 1, p. 241-262.

UZZI, Brian. Social structure and competition in interfirm networks: the paradox of embeddedness. Administrative Science Quartely, v. 42, p. 35-67, 1997.

VILPOUX, Oliver F.; OLIVEIRA, Euler J. Instituições informais e governanças em arranjos produtivos locais. Revista de Economia Contemporânea, v. 14, n. 1, p. 85-111, 2010.

VILLELA, Lamounier E.; PINTO, Mario C.S. Governança e gestão social em redes empresariais: análise de três arranjos produtivos locais (APLs) de confecções no estado do Rio de Janeiro. Revista de Administração Pública, v. 43, n. 5, p. 1067-1089, nov./dez. 2009.

Mário Sacomano Neto é professor do Programa de Mestrado e Doutorado em Administração da Faculdade de Gestão e Negócios da Universidade Metodista de Piracicaba (PPGA/Unimep). E-mail: msacomano@ unimep.br.

Luiz Fernando de Oriani e Paulillo é professor associado do Departamento de Engenharia de Produção e do Programa de Pós-Graduação em Gestão da Produção da Universidade Federal de São Carlos (UFSCar). E-mail: dlfp@power.ufscar.br. 